\title{
Neurotrophic effects of perfluorocarbon emulsion gel: a pilot study
}

Jonathan Isaacs*, Ilvy Friebe, Satya Mallu and Keith Bachman

\begin{abstract}
Background: Positive neurotrophic effects of hyperbaric oxygen treatment may be more easily achieved by applying a Perflourocarbon (PFC) emulsion gel to the repair site. PFCs are halogen substituted carbon oils with unique oxygen transport potentials that are capable of increasing oxygen availability in local tissues. The purpose of this study was to determine if the application of a PFC emulsion to a repaired nerve would improve recovery.

Materials and methods: The left tibial nerve of 21 immature female Sprague-Dawley rats was transected, immediately repaired, and then circumferentially coated with PFC gel (Group A, n = 7), PFC-less gel (Group B, $n=$ 7), or nothing (suture only, Group $C, n=7$ ). At eight weeks post surgery, electrophysiological testing and histological and morphological analysis was performed.

Results: No statistically significant differences between experimental groups were found for muscle size and weight, axon counts, or nerve conduction velocity. Group A had a significantly smaller G-ratio than Groups B and C $(p<.0001)$.

Conclusion: Overall results do not indicate a functional benefit associated with application of a PFC emulsion gel to rodent tibial nerve repairs. A positive effect on myelination was seen.
\end{abstract}

Keywords: Perfluorocarbons, Nerve Repair, Nerve Regeneration

\section{Background}

Despite significant advances in our understanding of nerve regeneration over the past six decades, achieving consistent satisfactory results following major nerve repair or reconstruction remains a challenge. Enhancement of the local biological environment towards a more neurosupportive environment is a common strategy aimed at improving nerve repair outcomes[1,2]. Strategies to increase tissue oxygenation at the repair site have received some attention in the past, though this has generally focused on hyperbaric oxygenation (HBO). Hyperbaric oxygenation treatment to improve nerve regeneration, involves emersion of the subject (patient or animal) in a pressurized and enriched oxygen environment for several hours at a time following the nerve repair. Results of this approach are mixed, but several reports suggest a positive effect[3-7].

\footnotetext{
* Correspondence: jisaacs@mcvh-vcu.edu
Division of Hand Surgery, Department of Orthopaedic Surgery, Virginia

* Correspondence: jisaacs@mcvh-vcu.edu Commonwealth University Health Systems, 1200 East Broad Street, P.O. Box 980153, Richmond, VA, USA
}

(C) 2011 Isaacs et al; licensee BioMed Central Ltd. This is an Open Access article distributed under the terms of the Creative Commons Attribution License (http://creativecommons.org/licenses/by/2.0), which permits unrestricted use, distribution, and reproduction in any medium, provided the original work is properly cited. to the expensive pressurized oxygenation chamber, the investment of prolonged unproductive periods of time within the chamber, and the possibly negative effects of fluctuating oxygen tensions associated with interval treatment schedules (i.e. high oxygenation levels will drop once the subject leaves the chamber). A less constrained approach for enhanced oxygen therapy may be possible through the use of perfluorocarbons. Perfluorocarbons are highly non-polar, biologically inert oils (first discovered during development of the atomic bomb), which possess unique gas transport potential. Perfluorocarbons (PFC) exhibit oxygen solubilities a factor of about $50 \times$ greater than that of water[8]. When applied around a nerve repair, PFCs may be able to provide local oxygen transport to damaged tissues without the disadvantages associated with $\mathrm{HBO}$. The purpose of this study is to evaluate the effects of a PFC emulsion gel on functional nerve regeneration. 


\section{Methods}

The perfluorocarbon gel used was prepared using a proprietary PFC similar in properties and oxygen solubility to perfluorodecalin. The gel was prepared in a manner similar to that describe by Moore[9]. The isolated gel contained about $87 \mathrm{wt} \%$ of the PFC and was heat sterilized at $122^{\circ} \mathrm{C}$ for 2 hours before use.

Twenty-one immature (3 month old) Sprague-Dawley rats were used for study after obtaining necessary approval from our institution's animal review board in accordance with national guidelines. All animals were housed in a temperature and humidity controlled environment with 12:12 day-night cycle and were provided food and water ad libitum. The rats were divided into three groups $(\mathrm{N}=7)$, A (repair with application of PFC emulsion gel), B (repair with application of PFC-less gel carrier only), and $\mathrm{C}$ (repair only). For all procedures, anesthesia was induced with $5 \%$ isoflurane in a closed chamber and maintained using 2-3\% isoflurane via nose cone inhalation. Surgical manipulations of the left hind limb nerves were performed under sterile conditions. The sciatic, tibial, and peroneal nerves were exposed through a standard biceps femoris-semitendinosis muscle splitting approach. The tibial nerve was isolated and transected one centimeter distal to the bifurcation from the sciatic nerve. Under operating microscope magnification, the cut ends of the tibial nerve were immediately co-apted with two 10-0 nylon epineural sutures placed 180 degrees apart. The repair site for groups A and B were circumferentially coated with PFC emulsion gel (Group A) or gel carrier only (Group B). The wounds were closed with 4-0 nonabsorbent monofilament and the animals allowed to recover from anesthesia before being returned to their cages. Post-operative analgesia was consistently accomplished with subcutaneous administration of buprenorphine $0.5 \mathrm{mg} / \mathrm{kg}$ and acetaminophen $272 \mathrm{mg} / 100 \mathrm{cc}$ added to the drinking water.

Final testing took place 8 weeks after the initial surgery. After the induction of general anesthesia, both the right and left sciatic nerves were exposed to allow testing on both the experimental and control hind limbs extremities. The sciatic nerve was isolated at the sciatic notch and proximal branches of the sciatic nerve transected to reduce muscle contraction and reduce interference. Two bipolar electrodes were placed on the isolated nerve with the stimulating electrode positioned at the proximal sciatic nerve and the recording bipolar electrode placed under the tibial nerve distally (with the interval space recorded for nerve conduction velocity calculation). Single square pulses of $0.02 \mathrm{msec}$ duration were applied while gradually increasing the strength of the stimulus until a maximum compound action potential waveform was achieved. This maximum stimulus was applied three times to each nerve and latency, base to peak amplitude, and peak to peak amplitude measured and recorded using a PowerLab data acquisition system (ADInstruments, Inc., Colorado Springs, CO) and an Apple iBook laptop computer (Cupertino, California).

Once nerve testing was complete, the tibial nerves and gastrocnemius muscles were harvested and fixed in 10\% formalin solution. Nerve sections were obtained $5 \mathrm{~mm}$ proximal and $5 \mathrm{~mm}$ distal to the repair site and stained with toludine blue for histological analysis (Figure 1). Analysis consisted of averaged axon counts per 5 random high power fields (40× magnification) and G-ratio assessments using the same high power fields. Axon counts were performed manually using Image 1.42 software (NIH website) and bias avoided by using the same five areas in each specimen. G-ratios were calculated by measuring the diameter of axons and dividing by the total diameter of that axon plus the surrounding myelin sheath. The gastrocnemius muscles were harvested from both hind limbs for diameter and weight measurements. The animals were euthanized with an intraperitoneal overdose of Euthasol $(150 \mathrm{mg} / \mathrm{kg})$.

Statistical analysis was performed using the ANOVA and Tukey's post test analysis, comparing the individual experimental groups versus all control groups, as well as the experimental groups to each other.

\section{Power analysis}

Power analysis sample size determination was based on standard deviations and reported differences noted in similar studies and using GraphPad StatMate software (GraphPad Software, Inc., San Diego, CA). The study by Eguiluz-Ordonez et al. used a similar rodent sciatic nerve model but looked at the effect of post repair

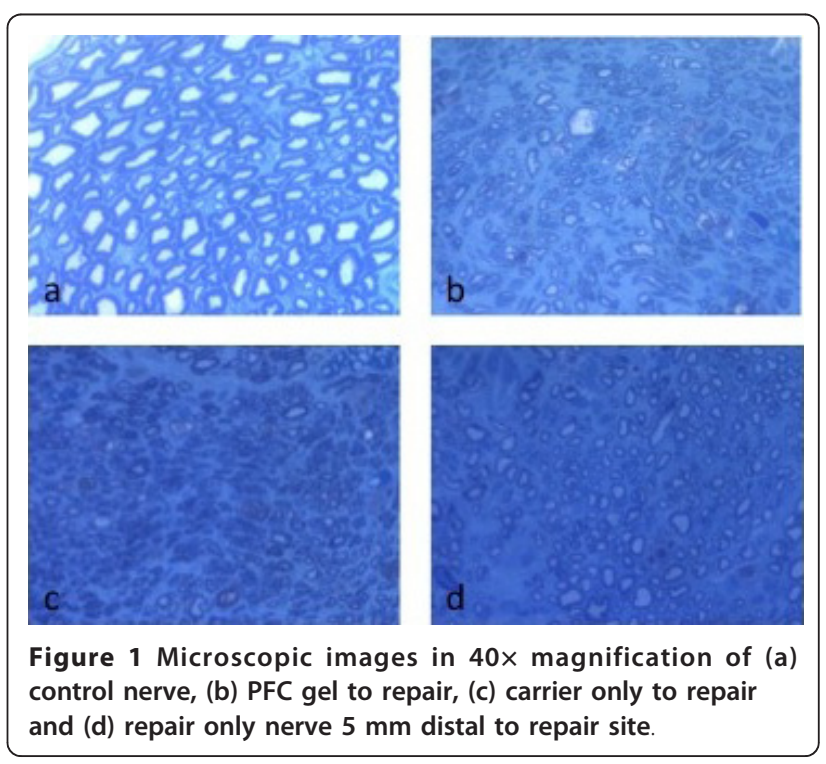


exposure to HBO. They found a statistically significant difference in motor latency (mean difference $.46 \mathrm{~ms}$, average Standard Deviation 0.34) with 10 rats in each group[6]. To achieve $90 \%$ power, seven rats in each group would demonstrate this difference if a similar standard deviation is expected.

\section{Results}

\section{Muscle Weight and Diameter}

For all experimental limbs, the gastrocnemius muscle measurements demonstrated statistically significant lighter weights and smaller diameters $(\mathrm{p}<0.0001)$ when compared with control limbs. The average weight and diameter of the experimentally manipulated muscles were $59 \%$ and $73 \%$ of the control side, respectively. There was no statistically significant difference in muscle size or weight between the three experimental groups (Table 1).

\section{Axon Count}

There was no statistically significant difference in axon counts $(p=0.09)$ per averaged high power field between the experimental and control groups, nor within the experimental groups (Table 1).

\section{Nerve Conduction Velocity}

There was a significant increase in tibial nerve motor latency $(\mathrm{p}<0.05)$, a decrease in tibial nerve amplitude $(\mathrm{p}<0.0001)$ in all three experimental groups compared to the control nerves but no differences between the experimental groups (Table 1).

\section{Histomorphometry}

There was a significantly increased G-ratio in the experimental groups compared to the control groups ( $p$ $<0.05)$. Among the experimental groups, Group A (PFC) had a significantly smaller G-ratio than Groups B and $\mathrm{C}(\mathrm{p}<0.0001)$ (Table 1$)$.

\section{Discussion}

Perfluorocarbons are unique compounds created when hydrocarbon chains undergo a hydrogen substitution with fluorine molecules. The subsequent oils are stable, inert, and have low surface tensions. Because they are highly non-polar and extremely hydrophobic, they will not bind to proteins and are usually lipophilic. Used in a variety of industrial and medical applications, PFCs possess impressively high oxygen (and other gas) solubility potentials which has spurred interest in a potential role as a "blood substitute". Oxygen molecules do not bind to the perfluorcarbon molecules (like they do to hemoglobin), but rather are trapped in between the molecules. This dissolved oxygen can be made available to surrounding tissues in certain circumstances [8]. When applied directly to a tissue bed, PFC gel has also been shown to improve wound healing[10]. We have hypothesized that application of a PFC emulsion gel around a repaired nerve might be expected to increase oxygen availability at the repair site and subsequently result in improved nerve regeneration.

Possible beneficial mechanisms of improved oxygenation on nerve regeneration include promotion of survival of marginal tissue, reduced edema and improved microcirculation, and up-regulation of growth factors [11]. Additionally, low oxygen tension has been correlated with scar tissue formation[12,13]. Scar tissue can block regenerating axons acutely or, more chronically, can cause secondary compression resulting in "strangulation" of the nerve and traction neuritis. Both can inhibit nerve function and may contribute to chronic neuropathic pain.

Increased oxygen tissue saturation as seen with $\mathrm{HBO}$ treatment has demonstrated potential benefits for nerve regeneration in both experimental and clinical settings. Zamboni et al. demonstrated improved functional recovery (walking track analysis) and decreased perineural scarring in rats treated with hyperbaric oxygen (HBO)

Table 1 Results of testing for all three experimental groups and control limbs

\begin{tabular}{|c|c|c|c|c|c|c|c|c|}
\hline & \multicolumn{2}{|c|}{ Exp -A (PFC) } & \multicolumn{2}{|c|}{ Exp -B (Gel) } & \multicolumn{2}{|c|}{ Exp -C (repair only) } & \multicolumn{2}{|l|}{ Control } \\
\hline & mean & SD & mean & SD & mean & SD & mean & SD \\
\hline Axon Count & 175.0 & 37.66 & 184.9 & 16.56 & 189.3 & 31.66 & 189.7 & 28.45 \\
\hline Muscle Diameter (mm) & 6.19 & 1.06 & 6.82 & 0.38 & 7.76 & 1.09 & 9.45 & 0.54 \\
\hline G-ratio & $0.6136^{*}$ & 0.1322 & 0.6863 & 0.0808 & 0.6858 & 0.0974 & $0.6465^{* *}$ & 0.0749 \\
\hline Muscle Weight (g) & 1.119 & 0.1299 & 1.152 & 0.1002 & 1.241 & 0.1070 & $1.998^{* *}$ & 0.2112 \\
\hline Motor Latency (msec) ( $\mathrm{N}$ to $\mathrm{N}$ ) & 2.459 & 0.3596 & 2.671 & 0.3974 & 2.477 & 0.3406 & $1.944^{* *}$ & 0.3942 \\
\hline Motor Latency (msec) (N-M) & 3.030 & 0.4727 & 3.094 & 0.9046 & 2.646 & 0.6688 & $2.362^{* *}$ & 0.3689 \\
\hline $\begin{array}{l}\text { Amplitude }(\mu \mathrm{V}) \\
\text { Base to Peak }\end{array}$ & 1833 & 1292 & 2788 & 3028 & 2675 & 1255 & $5983^{* *}$ & 3908 \\
\hline $\begin{array}{l}\text { Amplitude }(\mu \mathrm{V}) \\
\text { Peak to Peak }\end{array}$ & 3084 & 2031 & 3611 & 3287 & 4070 & 2211 & $8980^{* *}$ & 6465 \\
\hline
\end{tabular}

* statistically significant difference to Exp-B and Exp-C

** statistically significant to all $\operatorname{Exp}(A, B, C)$ groups 
(2.5 ATA/90 min/BID/7 days) following sciatic nerve injury (with nerves "stripped" of extrinsic blood supply) [3]. Using electron and light microscopy, Bradshaw et al. found more complete recovery of crushed rabbit sciatic nerves following $\mathrm{HBO}$ treatment[4]. Likewise, Haapaniemi et al. demonstrated improved axonal regeneration into nerve grafts when experimental rats received $\mathrm{HBO}$ treatment immediately following repair[5]. Eguiluz et al., while unable to demonstrate histological improvement with $\mathrm{HBO}$ treatment, noted improved functional and electrophysiological recovery in a rat sciatic nerve injury [6]. From a clinical perspective, Zhao reported on the beneficial effects of $\mathrm{HBO}$ combined with prompt surgical repair of nerve injuries[7].

Similar benefits as seen with HBO treatment were not demonstrated in our study. Morphological and electrophysiological data did not demonstrate any significant positive or negative effect when compared to either the carrier gel group or to the repair only group. A lower G-ratio, however, indicating a higher myelin to axon diameter ratio, was found in the PFC group. Similar positive effects on myelination have been seen with HBO $[4,14]$. Though this may represent faster axon regeneration and maturation (as has also been associated with $\mathrm{HBO}$ treatment in other rodent nerve repair models $[5,15]$ ), our study design did not specifically evaluate this variable and the exact significance or etiology of this finding is not known. Our evaluation period of only 8 weeks after nerve repair, however, was chosen specifically to identify this type of subtle difference in nerve regeneration between groups as longer recovery periods in similar rodent models have been recently associated with a "blow though effect" - eventually resulting in robust axonal regeneration regardless of treatment variables[16].

Our failure to demonstrate definite neurotrophic benefits with the PFC emulsion gel, however, has several possible explanations. First, although oxygen delivery to the nerve should have improved theoretically with PFC application, this was unable to be verified and without this effect, the emulsion gel would have no beneficial properties. Though this seems like a grave oversight in the study design, it must be pointed out that accurate measurements of oxygen tension at an in vivo nerve repair site (such as in this model) would be impossible. Furthermore, none of the already referenced studies regarding the effects of $\mathrm{HBO}$ on nerve healing and regeneration confirmed increased perineural or neural oxygen tension. Second, oxygenation (or perfusion) of the neural tissue may not have been an issue with this straightforward repair model[17] and the potential benefits of improving oxygenation may only be seen with ischemic tissue. A "rescue effect" has been demonstrated in experimental ischemic nerve tissue treated with $\mathrm{HBO}$
[18]. Other studies, however, fail to support this explanation. No functional or histological effect was seen with $\mathrm{HBO}$ treatment in an entubulated, acellular, or "hypoxic" rodent nerve repair model[15,19-21].

The final possible explanation for the lack of neurotrophic benefit seen in our study is that the results of previous HBO studies are overstated and that increased oxygenation at the nerve repair site may have no effect or may even be potentially harmful. In contrast to the supportive studies already cited, other studies have failed to demonstrate any benefit of $\mathrm{HBO}$ on nerve regeneration $[19,22,23]$. Potential counter productive effects of HBO could include decreased inflammatory cell responses[24] (which might affect macrophages necessary to clear debris from the endoneural tubes which is essential for axon regneration), though no specific macrophage effect has been demonstrated with $\mathrm{HBO}$ [21], and we did not evaluate macrophages in our study. Additionally, $\mathrm{HBO}$ has been demonstrated to increase nitrous oxide (NO) production[25]. Nitrous oxide may actually inhibit nerve regeneration and even be neurotoxic[26-28].

The above theories and apparently contradictory experimental study results may not be in complete conflict. It is likely that the situation is more complicated than presented and that there may be a "sweet spot" for oxygen levels. Too little or too much oxygen may both be detrimental to nerve regeneration. In this study, PFC emulsion gel when applied directly to a primary rodent tibial nerve repair increased myelination of regenerating axons but did not demonstrate any net positive neurotrophic effect. Further study to confirm local tissue effects of PFC gel application as well as a dose response curve would be appropriate before any final conclusions are made.

\section{Conclusion}

Although increased axonal myelination was noted, this was not associated with functional benefit following the application of a PFC emulsion gel to a tibial nerve repair in a rodent model.

\section{Authors Information}

Co-author's contact information:

Ilvy Friebe, M.D.

1200 East Broad Street

P.O. Box 980153

Richmond, VA 23298

ifriebe@mcvh-vcu.edu

Phone: 804-828-3815

Fax: 804-828-4762

Satya Mallu, M.D.

1200 East Broad Street

P.O. Box 980153 
Richmond, VA 23298

smallu@mcvh-vcu.edu

Phone: 804-828-3815

Fax: 804-828-4762

Keith Bachman, B.S.

3106 Ludlow Road

Shaker Heights, OH 44120

Krb3b.uva@gmail.com

Phone: 804-432-0025

\section{Authors' contributions}

$J I$ designed the project and wrote the manuscript. SM oversaw the rodent surgeries and was assisted by either IF or KB. GH and MQ developed and prepared the PFC emulsion gel. All authors read and approved the final manuscript.

\section{Competing interests}

The authors declare that they have no competing interests.

Received: 29 April 2011 Accepted: 23 November 2011

Published: 23 November 2011

\section{References}

1. Yin Q, Kemp GJ, Frostick SP: Neurotrophins, neurones and peripheral nerve regeneration. J Hand Surg [Br] 1998, 23:433-437.

2. Terzis JK, Sun DD, Thanos PK: Historical and basic science review: past, present, and future of nerve repair. J Reconstr Microsurg 1997, 13:215-225.

3. Zamboni WA, Brown RE, Roth AC, Mathur A, Stephenson LL: Functional evaluation of peripheral-nerve repair and the effect of hyperbaric oxygen. J Reconstr Microsurg 1995, 11:27-29, discussion 29-30

4. Bradshaw PO, Nelson AG, Fanton JW, Yates T, Kagan-Hallet KS: Effect of hyperbaric oxygenation on peripheral nerve regeneration in adult male rabbits. Undersea Hyperb Med 1996, 23:107-113.

5. Haapaniemi T, Nylander G, Kanje M, Dahlin L: Hyperbaric oxygen treatment enhances regeneration of the rat sciatic nerve. Exp Neurol 1998, 149:433-438

6. Eguiluz-Ordonez R, Sanchez CE, Venegas A, Figueroa-Granados V, Hernandez-Pando R: Effects of hyperbaric oxygen on peripheral nerves. Plast Reconstr Surg 2006, 118:350-357, discussion 358-359.

7. Zhao DW: [Therapeutic effect of hyperbaric oxygen on recovery of surgically repaired peripheral nerve injury]. Zhonghua Wai Ke Za Zhi 1991, 29:118-120, 143

8. Spiess BD: Perfluorocarbon emulsions as a promising technology: a review of tissue and vascular gas dynamics. J Appl Physiol 2009, 106:1444-1452

9. Moore R: Preparation of a gel having gas transporting capacity. US; 19814569784.

10. Davis SC, Cazzaniga AL, Ricotti C, Zalesky P, Hsu LC, Creech J, Eaglstein WH, Mertz PM: Topical oxygen emulsion: a novel wound therapy. Arch Dermatol 2007, 143:1252-1256.

11. Sanchez EC: Hyperbaric oxygenation in peripheral nerve repair and regeneration. Neurol Res 2007, 29:184-198.

12. Norman JT, Clark IM, Garcia PL: Hypoxia promotes fibrogenesis in human renal fibroblasts. Kidney Int 2000, 58:2351-2366.

13. Falanga $V$, Zhou $L$, Yufit $T$ : Low oxygen tension stimulates collagen synthesis and COL1A1 transcription through the action of TGF-beta1. J Cell Physiol 2002, 191:42-50.

14. Liu QL, He BP: Effects of hyperbaric oxygen therapy on rat sciatic nerve injury. Undersea Hyperb Med 1994, 21:341-343.

15. Bajrovic FF, Sketelj J, Jug M, Gril I, Mekjavic IB: The effect of hyperbaric oxygen treatment on early regeneration of sensory axons after nerve crush in the rat. J Peripher Nerv Syst 2002, 7:141-148.

16. Brenner MJ, Moradzadeh A, Myckatyn TM, Tung TH, Mendez AB, Hunter DA, Mackinnon SE: Role of timing in assessment of nerve regeneration. Microsurgery 2008, 28:265-272.

17. Zochodne DW: The microenvironment of injured and regenerating peripheral nerves. Muscle Nerve Suppl 2000, 9:S33-38.
18. Kihara M, McManis PG, Schmelzer JD, Kihara Y, Low PA: Experimental ischemic neuropathy: salvage with hyperbaric oxygenation. Ann Neurol 1995, 37:89-94

19. Santos PM, Zamboni WA, Williams SL, Covey JF, Kienstra MA: Hyperbaric oxygen treatment after rat peroneal nerve transection and entubulation. Otolaryngol Head Neck Surg 1996, 114:424-434.

20. Santos PM: A functional model system of an hypoxic nerve injury and its evaluation. Laryngoscope 2000, 110:845-853

21. Nishiura $Y$, Haapaniemi T, Dahlin LB: Hyperbaric oxygen treatment has different effects on nerve regeneration in acellular nerve and muscle grafts. J Peripher Nerv Syst 2001, 6:73-78.

22. Haapaniemi T, Nishiura Y, Dahlin LB: Functional evaluation after rat sciatic nerve injury followed by hyperbaric oxygen treatment. J Peripher Nerv Syst 2002, 7:149-154.

23. Santos PM, Williams SL, Covey J: Peroneal motor nerve crush injury and hyperbaric oxygen effect. Laryngoscope 1995, 105:1061-1065.

24. Buras J: Basic mechanisms of hyperbaric oxygen in the treatment of ischemia-reperfusion injury. Int Anesthesiol Clin 2000, 38:91-109.

25. Buras JA, Stahl GL, Svoboda KK, Reenstra WR: Hyperbaric oxygen downregulates ICAM-1 expression induced by hypoxia and hypoglycemia: the role of NOS. Am J Physiol Cell Physiol 2000, 278 C292-302.

26. Hess DT, Patterson SI, Smith DS, Skene JH: Neuronal growth cone collapse and inhibition of protein fatty acylation by nitric oxide. Nature 1993, 366:562-565.

27. Zochodne DW, Misra M, Cheng C, Sun H: Inhibition of nitric oxide synthase enhances peripheral nerve regeneration in mice. Neurosci Lett 1997, 228:71-74

28. Beal MF: Mitochondria, free radicals, and neurodegeneration. Curr Opin Neurobiol 1996, 6:661-666.

doi:10.1186/1749-7221-6-11

Cite this article as: Isaacs et al:: Neurotrophic effects of perfluorocarbon emulsion gel: a pilot study. Journal of Brachial Plexus and Peripheral Nerve Injury 2011 6:11.

\section{Submit your next manuscript to BioMed Central and take full advantage of:}

- Convenient online submission

- Thorough peer review

- No space constraints or color figure charges

- Immediate publication on acceptance

- Inclusion in PubMed, CAS, Scopus and Google Scholar

- Research which is freely available for redistribution

Submit your manuscript at www.biomedcentral.com/submit
C Biomed Central 